\title{
Descriptions of Eubacterium timidum sp. nov., Eubacterium brachy sp. nov., and Eubacterium nodatum sp. nov. Isolated from Human Periodontitis
}

\author{
LILLIAN V. HOLDEMAN,' ELIZABETH P. CATO,' J. A. BURMEISTER, ${ }^{2}$ aNd W. E. C. MOORE \\ Anaerobe Laboratory, Virginia Polytechnic Institute and State University, VCU Clinical Research Center \\ for Periodontal Disease, Blacksburg, Virginia $24061^{1}$ and School of Dentistry, VCU Clinical Research \\ Center for Periodontal Disease, Virginia Commonwealth University, Richmond, Virginia $23298^{2}$
}

Three new species of Eubacterium, E. timidum, E. brachy, and E. nodatum, which were isolated principally from subgingival areas associated with periodontitis, are described. All are anaerobic, gram-positive, non-saccharolytic rods. They are differentiated from each other and from other non-saccharolytic species of eubacteria by acid and gas products in broth cultures and by morphological and growth characteristics. The type strains for the species are as follows: E. timidum, ATCC 33093; E. brachy, ATCC 33089; and E. nodatum, ATCC 33099. These species were detected in 35 to $42 \%$ of the subgingival samples examined and, where present, constituted 3 to $57 \%$ of the cultivable flora. Strains of these species were isolated only occasionally from the adjacent supragingival areas sampled.

During quantitative and qualitative studies of the bacterial flora of samples from human subjects with periodontitis, we isolated numerous strains of anaerobic, gram-positive rods that did not have characteristics conforming to those of any of the presently recognized species. In this report we present the characteristics of strains of three of these groups and propose an appropriate named taxon for each of them.

\section{MATERIALS AND METHODS}

General. Unless otherwise stated, cultures were in prereduced media prepared as described previously (1) and kept anaerobic during inoculation by flushing with oxygen-free carbon dioxide. Anaerobic plates were incubated in vented GasPak (BBL Microbiology Systems, Cockeysville, Md.) jars with rejuvenated catalyst pellets in an atmosphere containing $90 \%$ hydrogen and $10 \%$ carbon dioxide.

Sites sampled. Two separate sites were sampled. Most of the organisms were isolated from samples obtained from the bottom and sides of the space between the tooth and the gingiva, apical to the gingival margin, of sites with chronic, destructive inflammation of the periodontium. This disease is termed periodontitis. All such sites sampled (hereafter referred to as subgingival) were classified as representing either a moderate or a severe disease state. Sites representing a moderate disease state had 5 to $7 \mathrm{~mm}$ of probeable depth and were in subjects 35 years of age or older. The sites representing a severe disease state had $7 \mathrm{~mm}$ or more of probeable depth and were in subjects 30 years of age or younger. Samples also were collected from the same tooth surface coronal to the gingival margin. These samples are termed supragingival samples.

Samples. Samples were removed with replaceable tip Morse scalers (size 00 ) that had been nickel plated.
Scaler tips with samples were placed immediately in prereduced, anaerobically sterilized peptone-yeast extract (PY) broth kept anaerobic by flushing with oxygen-free carbon dioxide. Suspensions of organisms were prepared by vigorously shaking (with a Vortex mixer for 5 to $10 \mathrm{~s}$ ) the tube containing PY broth, sample, scaler tip, and glass beads (diameter, 74 to 110 $\mu \mathrm{g})$. Serial 10 -fold dilutions were made in $0.9 \mathrm{ml}$ of gelatin-salts diluting fluid (1), and $0.1 \mathrm{ml}$ of each dilution to be cultured was inoculated into each of duplicate tubes of molten agar isolation medium cooled to $54^{\circ} \mathrm{C}$. The inoculum and agar were mixed by gently inverting the stoppered tube; the tube was then spun around a horizontal axis until the agar solidified. All original culturing of each sample was completed within about $45 \mathrm{~min}$ after the sample was taken.

After the roll tubes had been incubated for 5 days, 20 to 30 colonies were picked in a randomized manner from the highest dilution that contained 30 or more colonies. The roll tubes were continuously flushed with oxygen-free $\mathrm{CO}_{2}$ while the colonies were being picked. Colonies were picked into the same type of medium in which they were originally cultured, but with agar omitted.

Media. Strains were isolated either in supplemented brain heart infusion agar (BHIA) (1) supplemented with $5 \mathrm{ml}$ of serum, $7 \mathrm{ml}$ of rumen fluid, 0.02 $\mathrm{g}$ of formate, $0.02 \mathrm{~g}$ of fumarate, and $400 \mu \mathrm{g}$ of cocarboxylase per $100 \mathrm{ml}$ or in supplemented chopped meat broth agar. To prepare the chopped meat broth agar, lean ground beef was boiled with $\mathrm{NaOH}$, and the infusion was cooled and filtered as previously described (1). The filtrate was supplemented with the following (per $700 \mathrm{ml}$ ): Trypticase, (BBL Microbiology Systems), $22.5 \mathrm{~g}$; yeast extract, $3.75 \mathrm{~g}$; fructose, $0.75 \mathrm{~g}$; pyruvic acid, $0.68 \mathrm{ml}$; formate-fumarate solution $(6 \%$ each), $3.5 \mathrm{ml} ; 1: 20$ Tween $80,0.3 \mathrm{ml}$; rumen fluid, 50 $\mathrm{ml}$; potassium phosphate, $3.75 \mathrm{~g}$; and resazurin solution (1), $3 \mathrm{ml}$. After boiling and cooling, cysteine hydrochloride, hemin, and vitamin $K_{1}$ were added to give 
final concentrations (per $700 \mathrm{ml}$ ) of $0.35 \mathrm{~g}, 37.5 \mathrm{mg}$, and $700 \mu \mathrm{g}$, respectively. A $12-\mathrm{ml}$ amount of chopped meat broth was dispensed anaerobically into tubes, each of which contained $0.24 \mathrm{~g}$ of agar. Before the medium was used, serum and cocarboxylase were added to the sterile molten agar to give concentrations of $5 \%$ and $400 \mathrm{mg} / 100 \mathrm{ml}$, respectively.

For anaerobic blood agar plates (BAP), $5 \mathrm{ml}$ of defibrinated rabbit blood was added to $100 \mathrm{ml}$ of supplemented BHIA (1). Rabbit blood hemolyzed by freezing and thawing was used to prepare blood-containing streak tubes.

Cultures for the isolation of deoxyribonucleic acid (DNA) were grown in brain heart infusion broth supplemented with $0.5 \%$ yeast extract and $0.5 \%$ glucose.

Tests. Inhibition of growth by sodium polyanetholsulfonate (SPS) was tested by a modification of the method described by Wilkins and West (6). Cultures were inoculated into $5 \mathrm{ml}$ amounts of Schaedler broth and Schaedler broth containing $0.05 \%$ SPS. The amount of growth in the medium with and without SPS was recorded after tubes had been incubated for 2 days. Peptostreptococcus anaerobius VPI 5750 was inoculated into one set of broths as a positive control (growth inhibited by SPS). The method of Babcock (J. B. Babcock, Abstr. Int. Congr. Microbiol. 12th, Abstr. no. I60, p. 190, 1978) was used to test for tyrosine degradation. The medium contained (per 100 ml) $4.4 \mathrm{~g}$ of Schaedler agar, $0.4 \mathrm{~g}$ of yeast extract, 0.3 $\mathrm{g}$ of L-tyrosine, and $1 \mathrm{mg}$ of vitamin $\mathrm{K}_{1}$; the $\mathrm{pH}$ was adjusted to 7.0. To keep the tyrosine in suspension, the flask of autoclave-sterilized medium was swirled as the plates were poured. Inoculum from an agar culture was spread onto the surface of the medium in a circle about $15 \mathrm{~mm}$ in diameter; the agar also was stabbed into the center of the inoculated area. Inoculated plates were incubated at $37^{\circ} \mathrm{C}$ in an anaerobe jar for 3 days and then examined for clearing of the area around the growth, which indicated tyrosine degradation. $P$. anaerobius VPI 5750 was used as a positive control.

Susceptibilities to chloramphenicol $(12 \mu \mathrm{g} / \mathrm{ml})$, clindamycin $(1.6 \mu \mathrm{g} / \mathrm{ml})$, erythromycin $(3 \mu \mathrm{g} / \mathrm{ml})$, penicillin $\mathrm{G}(2 \mathrm{U} / \mathrm{ml})$, and tetracycline $(6 \mu \mathrm{g} / \mathrm{ml})$ were tested by the broth-disk method (5).

The procedures used for other bacteriological tests and for chromatographic analyses of volatile and methylated fatty acids and of hydrogen have been described previously (1).

J. L. Johnson determined the guanine plus cytosine $(\mathrm{G}+\mathrm{C})$ content of the DNA preparations by the thermal melting point method (3), using an automatic recording spectrophotometer (Gilford Instrument Laboratories, Inc., Oberlin, Ohio). DNA from Escherichia coli $\mathrm{B}$ was included in each set of analyses as a standard.

\section{RESULTS AND DISCUSSION}

A total of 164 strains (Table 1) of anaerobic, gram-positive, non-saccharolytic rods with characteristics unlike those of previously described species was isolated. The strains clustered into three groups by morphological and growth characteristics and by gas and acid products in broth cultures (Table 2). Strains in group 1 produced almost no volatile acids and only trace amounts of succinate and could not be classified as belonging to Propionibacterium (no propionate produced) or to Actinomyces, Bifidobacterium, or Lactobacillus (no major lactate or succinate produced). They belonged in the genus Eubacterium. Strains in group 2 produced branchedchain volatile fatty acids, and strains in group 3 produced butyrate. These clearly were members of the genus Eubacterium as presently defined (2).

Because the organisms have characteristics unlike those of any described species of Eubacterium, we propose three new species: Eubacter. ium timidum, Eubacterium brachy, and Eubacterium nodatum. The characteristics of the species are given in Table 2 and in the following species descriptions. The incidence of these species in the periodontal samples studied is given in Table 3.

Eubacterium timidum sp. nov. (ti'mi.dum. L. neut. adj. timidum fearful, timid [referring to the slight or slow growth in clumps]). This species is composed of obligately anaerobic, nonsporeforming, nonmotile, gram-positive rods that are regular to slightly diphtheroid in shape (Fig. 1A). Cells from PY-glucose broth cultures were 0.8 to 1.6 by 1.6 to $3.1 \mu \mathrm{m}$. Cells were often arranged in clumps. Cells from actively growing cultures were gram positive; they often stained gram negative from older cultures.

Colonies. After incubation for 5 days in roll tubes (either enriched BHIA or chopped meat broth agar), colonies of all strains were 0.5 to 1.0 $\mathrm{mm}$ in diameter, lenticular, and transparent to translucent. After incubation for 2 days, surface colonies on BHIA or BHIA blood streak tubes were $0.2 \mathrm{~mm}$ in diameter, circular, entire, low convex, and transparent to translucent. Four of five strains tested did not grow on the surface of anaerobic blood agar plates. No hemolysis was produced around colonies on the BAP by the one strain that grew. Five of five strains tested grew on the surface of anaerobically incubated egg yolk agar plates, but they did not grow on egg yolk agar plates incubated in an aerobic atmosphere enriched with carbon dioxide to $5 \%$. Surface colonies on plates were similar to those in streak tubes.

Cultural characteristics. Broth cultures of all strains usually had only a small amount of smooth or slightly granular sediment and no, or only very slight, turbidity. Growth of all strains was inhibited by $2 \%$ oxgall but was neither inhibited nor enhanced by the addition of $0.02 \%$ Tween $80,5 \%$ rumen fluid, or $10 \%$ serum with cocarboxylase. Growth of all strains occurred only in the anaerobic portion of agar deep cul- 
TABLE 1. Sources of isolates studied

Site sampled

Specimen no. ${ }^{a}$ (isolate no $[\mathrm{s}]$. )

\begin{tabular}{ll}
\hline & E. timidum \\
Subgingival & D1B $(22,32) ; \mathrm{D} 2 \mathrm{~A}(28,32) ; \mathrm{D} 3 \mathrm{~B}(17) ; \mathrm{D} 7 \mathrm{~B}(7,14) ; \mathrm{D} 8 \mathrm{~B}(17) ; \mathrm{D} 9 \mathrm{~B}$ \\
& $(6,7,22) ; \mathrm{D} 10 \mathrm{~B} b(1,2,4,13,17,20,28) ; \mathrm{D} 10 \mathrm{D} b(9,10,11,12,21$, \\
& $25,26,27,28,29) ; \mathrm{D} 1 \mathrm{~B}(2) ; \mathrm{D} 12 \mathrm{~B}(15,19,28) ; \mathrm{D} 13 \mathrm{~B}(14) ; \mathrm{D} 14 \mathrm{~B}$ \\
& $(1,3,4,5,6,7,8,10,12,14,17,18,20,22,28,29,30) ; \mathrm{D} 15 \mathrm{~B}(8$, \\
& $9,10,12 \mathrm{~B}, 15,26,28) ; \mathrm{D} 19 \mathrm{~B}(18)$.
\end{tabular}

Supragingival

Subgingival

Supragingival

Subgingival

Supragingival

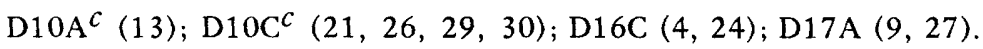

\section{E. bracby}

D1A (8A, 19A, 24, 27, 30, 31, 34, 38, 40); D1C (7); D2A (8, 36, 39); D3A (9); D3B (10); D4A (4, 6, 8, 15, 16, 18, 24, 29); D4B $(2,4,17$, 18A, 21A, 23B, 26B, 30); D6A (2, 4, 15, 17, 18, 20, 26, 27, 28, 29); D6B $(8 \mathrm{~B}, 23)$; D14B (11); D19B $(5,22)$.

D10A (20).

\section{E. nodatum}

D1B (38); D3B $(4,8,18)$; D6A $(5,9,11)$; D6B $(3,15,18,26)$; D8B $(18,19,22)$; D9B $(1,17)$; D10B $(3,8,9,11,16,21,23,25)$; D13B $(5,6,7,17,20,23 \mathrm{~A}, 26)$; D14B (9); D15B $(1,3,5,11,13,19,20$, $21,22,29,31)$; D18B $(2,14)$.

D18B $(2,14)$.

$a, b, c$ Specimen numbers with the same superscript represent two samples from the same site which were collected at different times. Specimens DIOA and DIOB were collected on 6 November 1978, and specimens DIOC and DIOD were collected on 31 January 1979.

TABLE 2. Salient characteristics of three groups of gram-positive, nonsporing rods-E. timidum, E. brachy, and $E$. nodatum-frequently isolated from cases of periodontitis ${ }^{\prime \prime}$

\begin{tabular}{|c|c|c|c|c|c|c|}
\hline \multirow{2}{*}{ Characteristic } & \multicolumn{2}{|c|}{$\begin{array}{l}\text { Group } 1 \\
\text { E. timidum }\end{array}$} & \multicolumn{2}{|c|}{$\begin{array}{l}\text { Group } 2 \\
\text { E. brachy }\end{array}$} & \multicolumn{2}{|c|}{$\begin{array}{c}\text { Group } 3 \\
\text { E. nodatum }\end{array}$} \\
\hline & $\begin{array}{l}\text { ATCC } \\
33093\end{array}$ & $\begin{array}{c}67 \\
\text { isolates }\end{array}$ & $\begin{array}{l}\text { ATCC } \\
33089\end{array}$ & $\begin{array}{c}47 \\
\text { isolates }\end{array}$ & $\begin{array}{l}\text { ATCC } \\
33099\end{array}$ & $\begin{array}{c}50 \\
\text { isolates }\end{array}$ \\
\hline \multicolumn{7}{|l|}{ Agar deep colonies } \\
\hline Lenticular & + & + & + & + & - & - \\
\hline Raspberry & - & - & - & - & + & + \\
\hline \multicolumn{7}{|l|}{ Acid products } \\
\hline Butyric & - & - & - & - & + & + \\
\hline Branched-chain & - & - & + & + & - & - \\
\hline Hydrogen in head-gas & $-(\mathrm{tr})$ & $-(\mathrm{tr})$ & + & + & - & - \\
\hline
\end{tabular}

${ }^{a}$ No strain hydrolyzed starch or esculin, produced indole or catalase, or reduced nitrate. No strain digested gelatin, milk, or meat. No strain produced acid from amygdalin, arabinose, cellobiose, erythritol, esculin, fructose, glucose, glycogen, inositol, lactose, maltose, mannitol, mannose, melezitose, melibiose, raffinose, rhamnose, ribose, salicin, sorbitol, starch, sucrose, trehalose, or xylose. In addition, adonitol, dextrin, dulcitol, galactose, glycerol, inulin, pectin, and sorbose were not fermented by ATCC 33093 and five other strains of E. timidum, ATCC 33089 and five other stains of $E$. brachy, and ATCC 33099 and five other stains of E. nodatum tested. 
TABLE 3. Incidence of E. timidum, E. brachy, and E. nodatum in samples from subgingival and supragingival areas associated with periodontitis

\begin{tabular}{lccc}
\hline Incidence & E. timidum & E. bracby & E. nodatum \\
\hline No. of isolates per 1410 total isolates & 67 & 47 & 50 \\
& & & \\
No. of sites where detected per total & & & \\
no. sites sampled & $13 / 31$ & $11 / 31$ & $11 / 31$ \\
$\quad$ Subgingival & $3 / 16$ & $1 / 16$ & $3 / 16$ \\
Supragingival & & & \\
No. of persons in which detected & & & \\
per no. persons sampled & $13 / 19$ & $7 / 19$ & $10 / 19$ \\
$\quad$ Subgingival & $3 / 16$ & $1 / 16$ & $3 / 16$ \\
$\quad$ Supragingival & & & \\
\hline
\end{tabular}

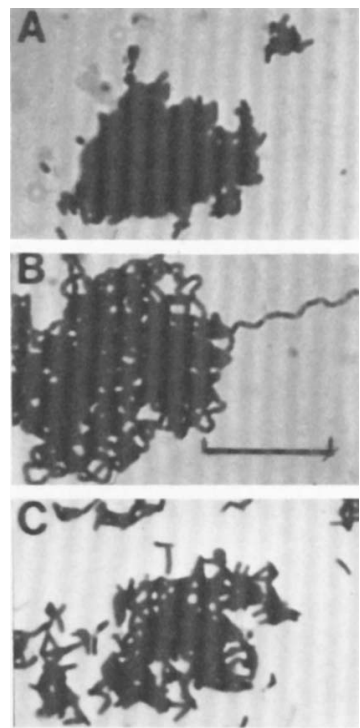

FIG. 1. Photomicrographs of Gram-stained cells from PY broth cultures of E. timidum ATCC 33093 (A), E. brachy ATCC 33089 (B), and E. nodatum ATCC 33099 (C). The bar in (B), which applies to all three photomicrographs, represents $10 \mu \mathrm{m}$.

tures. The type strain and five other strains tested (each from a different person) grew equally well at 37 and $45^{\circ} \mathrm{C}$ but did not grow at $30^{\circ} \mathrm{C}$.

Because the strains grew very poorly in all broth media tested, we were unable to obtain enough cells to extract DNA for a determination of the $\mathrm{G}+\mathrm{C}$ content.

Biochemical reactions and fermentation products. Distinctive characteristics of the species are presented in Table 2 . No strain produced ammonia from arginine or in PY broth cultures.
No gas was detected in agar deep cultures. Growth of the type strain and five other strains tested was inhibited by $6.5 \% \mathrm{NaCl}$ but was not inhibited by $0.05 \%$ SPS. Neither lecithinase nor lipase was produced on egg yolk agar plates by the six strains tested. Neutral red was reduced by six strains tested.

Only trace amounts ( 0.07 to $0.09 \mathrm{meq} / 100 \mathrm{ml}$ ) of acetate, formate, or succinate were detected from PY or PY-glucose cultures of all strains after incubation for 2 to 7 days. No, or only slight, hydrogen was detected in the headspace gas of all strains. Neither pyruvate nor lactate was utilized by the type strain or by five other strains tested.

The type strain and 29 other strains tested were susceptible to the test levels of chloramphenicol, clindamycin, and erythromycin; two were resistant to $2 \mathrm{U}$ of penicillin $\mathrm{G}$ per $\mathrm{ml}$, and eight were resistant to $6 \mu \mathrm{g}$ of tetracycline per $\mathrm{ml}$.

Type strain. The type strain is VPI D1B-22 (=ATCC 33093), which was isolated from a subgingival area which exhibited periodontitis.

The inability of $E$. timidum to use arginine as a substrate (4) and the shape and arrangement of the cells differentiated $E$. timidum from $E$. lentum, the species of Eubacterium which it most closely resembles. The inability of $E$. timidum to ferment any of the carbohydrate substrates tested differentiated it from members of the genus Actinomyces, which it resembled somewhat in cellular morphology.

E. timidum was detected in $42 \%$ of the subgingival samples and constituted 3 to $57 \%$ of the cultivable flora in those specimens from which it was isolated. It was isolated from $19 \%$ of the supragingival samples examined, where it represented 3 to $13 \%$ of the flora. 
Eubacterium brachy sp. nov. (bra'chy. M.L. neut. adj. brachy from Gk. brachy short [referring to the length of the cells]). Strains of this species are obligately anaerobic, nonmotile, nonsporeforming, short, gram-positive rods that occur predominantly in long chains (Fig. 1B). Cells from PY or PY-glucose broth cultures were 0.4 to 0.8 by 1 to $3 \mu \mathrm{m}$. Although some cells in a chain might be coccoid, definite rods could be seen upon close examination of the smears.

Colonies. After incubation for 5 days in roll tubes, colonies of all strains were 0.5 to $2.0 \mathrm{~mm}$ in diameter, lenticular to trifoliate, and transparent to opaque. After incubation for 2 days, surface colonies on supplemented BHIA streak tubes were less than $0.5 \mathrm{~mm}$ in diameter, circular, entire, low convex, white, shiny, and smooth. Surface colonies on chopped meat broth agar were similar to those on BHIA but were larger (1.0 $\mathrm{mm}$ in diameter). Surface growth was obtained more reliably on chopped meat broth agar than on BHIA tubes or anaerobic BAP.

Cultural characteristics. Broth cultures of all strains had a small amount of fine, granular to smooth sediment, often without turbidity. Broth cultures often required incubation for 2 to 3 days to attain maximum growth, which at best was $2+$, as graded on a scale of negative to $4+$. Growth of all strains was slightly inhibited by $20 \%$ oxgall but was neither inhibited nor stimulated by the addition of $0.02 \%$ Tween $80,5 \%$ rumen fluid, or $10 \%$ serum with cocarboxylase. The temperature for optimum growth was $37^{\circ} \mathrm{C}$; most strains did not grow at 30 or $45^{\circ} \mathrm{C}$. Growth occurred only in the anaerobic portion of agar deep cultures.

Because growth was so slight in all media tested, we were unable to obtain enough cells to extract DNA for a determination of the $\mathrm{G}+\mathrm{C}$ content.

Biochemical reactions and fermentation products. In addition to the characteristics presented in Table 2, growth was not inhibited by $0.05 \%$ SPS. No strain grew on anaerobically incubated tyrosine plates. A small amount of gas was produced in agar deep cultures that had reasonably good growth. The type strain and five other strains tested (each isolated from a different person) did not grow in $6.5 \% \mathrm{NaCl}$. The one strain (of five tested) that grew on anaerobically incubated BAP or egg yolk agar plates did not produce detectable hemolysis; no lecithinase or lipase activity was noted. Neutral red was sometimes reduced, apparently depending upon the amount of growth (because most strains grew as fine granules, it was difficult to obtain a uniform inoculum in each tube of substrate).

Major products from broth cultures (PY broth or PY broth plus any of several carbohydrates) of all strains after incubation for to 4 to 5 days averaged (in milliequivalents per $100 \mathrm{ml}$ ): isocaproate, 0.5 ; isovalerate, 0.3 ; and isobutyrate, 0.3 . Acetate $(0.1 \mathrm{meq} / 100 \mathrm{ml})$, formate $(0.15$ $\mathrm{meq} / 100 \mathrm{ml})$, and succinate $(0.15 \mathrm{meq} / 100 \mathrm{ml})$ were also often detected. Headspace gas of 5 day-old broth cultures contained 2 to $3 \%$ hydrogen. Neither lactate nor pyruvate was used. Ammonia was produced in PY broth cultures.

Of 30 strains tested, 23 produced sufficient growth in supplemented brain heart infusion broth for reliable interpretation of susceptibility tests. All 23 strains were susceptible to test levels of chloramphenicol, clindamycin, erythromycin, penicillin $\mathrm{G}$, and tetracycline.

Type strain. The type strain is VPI D6B-23 (=ATCC 33089), which was isolated from a subgingival area which exhibited periodontitis.

Because of the fermentation products and the occurrence of short cells in chains, this species resembled $P$. anaerobius. It initially appeared different from $P$. anaerobius because it did not grow as well in the usual media and definite rods could be seen in Gram stains. The inability of $E$. brachy to grow on the Schaedler agar-tyrosine plates and its ability to grow in the presence of $0.05 \%$ SPS were additional confirmation that this species was different from $P$. anaerobius.

$E$. brachy was detected in $35 \%$ of the subgingival samples and constituted 3 to $30 \%$ of the cultivable flora in those specimens from which it was isolated. One strain was isolated from 1 of the 16 supragingival samples examined. No strains were isolated from the subgingival area adjacent to this sample.

We have received for identification one strain of $E$. brachy (sent to us by Leona Stringer, Anaheim Memorial Hospital, Anaheim, Calif.) which was isolated, along with Fusobacterium nucleatum, from a lung abscess specimen collected by needle aspiration.

Eubacterium nodatum sp. nov. (no.da'tum. L. neut. participle nodatum entangled [referring to the tangled arrangement of the cells]). Strains of $E$. nodatum are obligately anaerobic, grampositive, nonmotile, nonsporeforming rods that occur in clumps in broth cultures. A small clump is shown in Fig. 1C to illustrate the shape of the cells. Most clumps were much larger. Cells were 0.5 to 0.9 by 2 to $12 \mu \mathrm{m}$. Cells appeared branched, somewhat filamentous, or club shaped.

Colonies. After incubation for 5 days in roll tubes, colonies of all strains were 0.5 to $2.0 \mathrm{~mm}$ in diameter, transluscent to opaque, and raspberry shaped. After incubation for to 2 to 4 days, surface colonies on BHIA streak tubes or anaer. obically incubated BAP were less than 0.5 to 1.0 $\mathrm{mm}$ in diameter, generally circular, entire to 
lobate, and heaped or with a berry-like appearance. The type strain and five other strains tested produced no hemolysis around colonies on anaerobically incubated BAP, and they did not grow on egg yolk agar plates incubated anaerobically.

Cultural characteristics. Broth cultures of all strains were not turbid and had flocculent, granular, or bread-crumb-type sediment. Growth was inhibited by $2 \%$ oxgall but was neither inhibited nor enhanced by the addition of $0.02 \%$ Tween $80,5 \%$ rumen fluid, or $10 \%$ serum with cocarboxylase. The temperature for optimum growth was $37^{\circ} \mathrm{C}$; most strains also grew at 30 and $45^{\circ} \mathrm{C}$. Only an occasional strain grew at $25^{\circ} \mathrm{C}$. Growth occurred only in the anaerobic portion of agar deep cultures. There was no growth on the surface of BAP incubated in air enriched with $\mathrm{CO}_{2}$ to $5 \%$.

Biochemical reactions. In addition to the characteristics given in Table 2, no gas was detected in agar deep cultures. Growth of the type strain and five other strains tested (each isolated from a different person) was inhibited by $6.5 \% \mathrm{NaCl}$ but not by $0.05 \%$ SPS. Ammonia was produced in PY broth cultures, and neutral red was usually reduced by these six strains.

The major product detected from PY or PYglucose broth cultures of all strains after incubation for 4 to 5 days was butyrate (approximately $1 \mathrm{meq} / 100 \mathrm{ml}$ ). Other products sometimes detected were (in milliequivalents per 100 $\mathrm{ml}$ ): acetate, 0.2 ; formate, 0.1 ; and succinate, 0.1 . No hydrogen was detected in headspace gas. Neither lactate nor pyruvate was used.

The 32 strains tested were susceptible to test levels of chloramphenicol, clindamycin, erythromycin, penicillin $\mathrm{G}$, and tetracycline.

The $\mathrm{G}+\mathrm{C}$ content of the DNA was $38 \mathrm{~mol} \%$ for the type strain and 36 to $38 \mathrm{~mol} \%$ for three other strains tested.

Type strain. The type strain is VPI D6A-5 (=ATCC 33099), which was isolated from a subgingival area associated with periodontitis.

Morphologically, strains of $E$. nodatum resemble members of the genus Actinomyces. However, unlike species of Actinomyces, strains of $E$. nodatum are non-saccharolytic and produce butyrate, presumably from peptone.

$E$. nodatum was detected in $35 \%$ of the subgingival samples examined and constituted 3 to $35 \%$ of the cultivable flora in those specimens from which it was isolated. It was isolated from $19 \%$ of the supragingival samples cultured, where it represented 3 to $7 \%$ of the flora.

Habitat and distribution. In the studies in which the species named and described here were detected, the culture isolation procedures yielded colony counts that equaled or exceeded the Gram-stained direct microscopic clump counts of the dispersed samples in the original tubes. Randomized sampling of the colonies provided a representative cross section of the bacterial populations in the sample sites.

The frequencies of occurrence and the concentrations of E. timidum, E. brachy, and E. nodatum in these subgingival samples suggest that these three species may contribute significantly to the disease state in moderate and severe adult periodontitis. Among the most frequently isolated of the 141 species, subspecies, or phenotypically different groups detected in these studies, only these three species of Eubacterium, Fusobacterium nucleatum, and Selenomonas sputigena increased in both incidence and concentration in subgingival samples from sites with severe as compared with moderate periodontitis. Unlike $F$. nucleatum, the three Eubacterium species and $S$. sputigena did not occur frequently or in high numbers in the adjacent supragingival flora.

Bacteroides melaninogenicus subsp. intermedius, several other Bacteroides species, and individual Actinomyces species which also are believed to be important in adult periodontitis were isolated with equal or slightly greater frequencies and numbers from periodontal pockets of adult patients with moderate disease, but they were less frequent and in lower concentrations than $E$. timidum, $E$. brachy, and $E$. nodatum from patients with severe periodontitis.

The slow formation of colonies and relatively poor growth of E. timidum, E. brachy, and $E$. nodatum on culture media, the morphological similarity of $E$. timidum and $E$. nodatum to Actinomyces species, and the metabolic and superficial morphological similarity of $E$. brachy to $P$. anaerobius may explain why these three new but relatively common species have not been reported previously from periodontal disease specimens.

\section{ACKNOWLEDGMENTS}

We gratefully acknowledge the help of K. Palcanis and R. R. Ranney, School of Dentistry, Virginia Commonwealth University, who selected the subjects and sites to be sampled and obtained the samples. We are especially grateful to $\mathrm{T}$. $\mathrm{O}$. MacAdoo, Department of Foreign Languages and Literature, Virginia Polytechnic Institute and State University, for suggesting appropriate specific epithets and their derivations. We appreciate the technical assistance of Barbara Harich, Jane Hungate, and Dianne Wall in the bacteriological analyses and of Carol Phelps in the determinations of the $\mathrm{G}+\mathrm{C}$ contents of the DNAs.

This work was supported by Public Health Service grant DE 05139-01 from the National Institute of Dental Research. The $\mathrm{G}+\mathrm{C}$ analyses were supported by Public Health Service grant DE 05218-01 from the National Institute of Dental Research. 


\section{REPRINT REQUESTS}

Address reprint requests to: Dr. Lillian V. Holdeman, Anaerobe Laboratory, Virginia Polytechnic Institute and State University, Blacksburg, VA 24061.

\section{LITERATURE CITED}

1. Holdeman, L. V., E. P. Cato, and W. E. C. Moore (ed.). 1977. Anaerobe laboratory manual, 4th ed. Virginia Polytechnic Institute and State University Anaerobe Laboratory, Blacksburg.

2. Holdeman, L. V., and W. E. C. Moore. 1974. Genus II. Eubacterium Prévot 1938, 294, p. 641-656. In R. E. Buchanan and N. E. Gibbons (ed.), Bergey's manual of determinative bacteriology, 8th ed. The Williams \& Wilkins, Co., Baltimore.

3. Marmur, J., and P. Doty. 1962. Determination of the base composition of deoxyribonucleic acid from its thermal denaturation temperature. J. Mol. Biol. 5:109-118.

4. Sperry, J. F., and T. D. Wilkins. 1976. Arginine, a growth-limiting factor for Eubacterium lentum. J. Bacteriol. 127:780-784.

5. Wilkins, T. D., and T. Thiel. 1973. A modified broth disk method for testing the antibiotic susceptibility of anaerobic bacteria. Antimicrob. Agents Chemother. 3: 350-356.

6. Wilkins, T. D., and S. E. H. West. 1976. Medium-dependent inhibition of Peptostreptococcus anaerobius by sodium polyanetholsulfonate in blood culture media. J. Clin. Microbiol. 3:393-396. 